\title{
Miller Fisher syndrome developing as a parainfectious manifestation of dengue fever: a case report and review of the literature
}

\author{
Nipun Lakshitha de Silva ${ }^{1 *}$ (D) Praveen Weeratunga ${ }^{1,2}$, Thirugnanam Umapathi $^{3}$, Neelika Malavige ${ }^{4}$ and \\ Thashi Chang ${ }^{1,2}$
}

\begin{abstract}
Background: Although dengue viral infections have emerged as one of the most important mosquito-borne diseases, neurological manifestations of dengue infections are uncommon. Guillain-Barré syndrome and Miller Fisher syndrome have been reported to occur as immune-mediated complications following dengue infection. We report the case of a patient who developed Miller Fisher syndrome during the acute phase of dengue fever suggesting that Miller Fisher syndrome may arise as a result of direct neurotropism of the dengue virus.

Case presentation: A 70-year-old Sri Lankan man with well-controlled diabetes mellitus and hypertension presented with fever of 3 days' duration, drooping of eyelids, dysarthria, and unsteady gait. He developed bilateral asymmetric partial ptosis, complete external ophthalmoplegia, bilateral palatal palsy, unilateral tongue weakness, ataxia, and areflexia from the second day of illness. He did not have limb weakness. He had evidence of acute dengue infection including progressive thrombocytopenia and leukopenia, positive dengue non-structural protein 1 antigen, dengue immunoglobulin $\mathrm{M}$ antibodies, and polymerase chain reaction detection of dengue virus genome in serum. Magnetic resonance imaging of his brain and cerebrospinal fluid analysis were normal. Polymerase chain reaction for dengue virus and immunoglobulin $\mathrm{M}$ antibodies in cerebrospinal fluid were negative. Nerve conduction studies showed axonal neuropathy. Antibodies (immunoglobulin G, immunoglobulin M, and immunoglobulin A) against GQ1b and GT1a were negative. He was treated with intravenously administered immunoglobulins and a recommended fluid regimen for dengue fever. He made a complete recovery from dengue fever in 7 days and Miller Fisher syndrome in 20 days.

Conclusions: This case report highlights the rare occurrence of Miller Fisher syndrome during the acute phase of dengue fever. Neurological manifestations may occur as a consequence of direct neurotropism of dengue virus.
\end{abstract}

Keywords: Dengue, Guillain-Barré syndrome, Miller Fisher syndrome

\section{Background}

Dengue fever (DF) is the second commonest mosquitoborne infection after malaria [1]. It is estimated that approximately 390 million dengue infections occur annually worldwide out of which only approximately 90 million cases are clinically apparent [2]. Dengue viral infections have been endemic in Sri Lanka since the

\footnotetext{
*Correspondence: nipunlak@gmail.com

${ }^{1}$ Professorial Unit in Medicine, National Hospital of Sri Lanka, Colombo, Sri Lanka

Full list of author information is available at the end of the article
}

mid-1960s while epidemics of dengue hemorrhagic fever (DHF) have been recurring for almost three decades.

Dengue infection is often subclinical or present with a mild, undifferentiated, self-limiting acute febrile illness (DF). However, a proportion of patients with DF develop life-threatening disease characterized by plasma leakage and vascular shock (DHF).

Neurological manifestations in dengue infection have been recognized since the latter part of the twentieth century [3]. The pathophysiological basis of neurological manifestations in dengue infection remains not fully 
understood. Although encephalopathy and encephalitis are most frequently reported, the spectrum of neurological manifestations continues to expand from myositis, myelitis, cerebellitis, maculopathy, and other neuro-ophthalmic complications and mononeuropathies to Guillain-Barré syndrome (GBS) [4,5]. GBS and its variants in dengue infection occur as immune-mediated complications 1 or more weeks after the acute infection $[4,6]$. We report the case of a patient who developed Miller Fisher syndrome (MFS) during the acute phase of DF suggesting that the dengue virus may have a direct neurotropic effect.

\section{Case presentation}

A 70-year-old Sri Lankan man with well-controlled diabetes mellitus and hypertension over 6 years developed acute onset, high-grade, intermittent fever associated with headache, arthralgia, myalgia, and nausea with no apparent focus of infection. On day 2 since onset of fever, he developed drooping of his eyelids and dysarthria. On day 3, he developed dysphagia and difficulty in walking because of unsteadiness. He did not experience any alteration of consciousness, seizures, sphincter dysfunction, limb weakness, or paresthesia. He was admitted to hospital on the third day of his illness. A timeline of the events starting from onset of fever is summarized in Table 1 . There was no history of recent respiratory or gastrointestinal infection, or immunization. He had not had any neurological diseases in the past. His current medications included losartan for hypertension and metformin for diabetes mellitus.

On examination, his body temperature was $38.5{ }^{\circ} \mathrm{C}$ while general examination and respiratory, cardiovascular, and abdominal examinations were normal. His heart rate was 76 beats per minute and his blood pressure was $140 / 90 \mathrm{mmHg}$. On neurological examination, he was noted to be conscious, alert, and oriented. He had bilateral asymmetric ptosis more on right side, mid-dilated pupils with sluggish reaction to light, and complete bilateral external ophthalmoplegia but without diplopia; optic fundi, visual fields, and acuity were normal. He had bilateral palatal weakness and tongue deviation to right side; the rest of his cranial nerves were normal. He had a broad-based ataxic gait, dysdiadochokinesia, and dysmetria; all tendon reflexes were absent; the rest of the neurological examination of limbs, including sensation, was normal.

Investigations revealed thrombocytopenia with a platelet count of $106 \times 10^{9} / 1$ on day 3 , which dropped further to $17 \times 10^{9} / 1$ on day 6 . His platelet count then gradually increased to $164 \times 10^{9} / 1$ by day 13 . His white cell count reduced to $4200 \times 10^{9} / 1$ on day 5 and then gradually increased to $7100 \times 10^{9} / 1$ on day 13 . Hematocrit was $40 \%$ and stable throughout the course of the illness. His creatinine was $99 \mu \mathrm{mol} / \mathrm{l}$; serum sodium $132 \mathrm{mmol} / \mathrm{l}$; and potassium $3.6 \mathrm{mmol} / \mathrm{l}$. Serum aspartate aminotransferase (AST) showed a rise from $115 \mathrm{U} / \mathrm{l}$ on day 3 to $243 \mathrm{U} / \mathrm{l}$ on day 5 and normalized to $43 \mathrm{U} / \mathrm{l}$ by day 10 . Alanine

Table 1 Timeline of events with diagnostic tests and interventions

\begin{tabular}{|c|c|c|c|}
\hline Day of illness & Events & Diagnostic tests & Interventions \\
\hline 01 & Onset of fever & & \\
\hline 02 & Right ptosis and dysarthria & & \\
\hline 03 & $\begin{array}{l}\text { Bilateral asymmetric ptosis, complete } \\
\text { ophthalmoplegia, mid-dilated pupils, } \\
\text { swallowing difficulty due to palatal } \\
\text { palsy, tongue deviation to right side, } \\
\text { ataxia, and areflexia }\end{array}$ & $\begin{array}{l}\text { Dengue NS-1 antigen positive } \\
\text { Dengue RT-PCR positive }\end{array}$ & $\begin{array}{l}\text { Admission to hospital, monitoring } \\
\text { and fluid management for dengue fever }\end{array}$ \\
\hline 04 & & Non-contrast CT (brain) - normal & $\begin{array}{l}\text { Intravenously administered polyclonal } \\
\text { immunoglobulin started, supportive therapy }\end{array}$ \\
\hline 06 & $\begin{array}{l}\text { Improvement of ophthalmoplegia } \\
\text { and ptosis, resolution of fever }\end{array}$ & $\begin{array}{l}\text { MRI (brain) - normal } \\
\text { Nerve conduction studies - evidence } \\
\text { of mild axonal polyneuropathy }\end{array}$ & \\
\hline 07 & & Dengue immunoglobulin $\mathrm{M}$ (serum) - positive & \\
\hline 08 & $\begin{array}{l}\text { Improvement of ataxia, ability to walk } \\
\text { without support }\end{array}$ & & $\begin{array}{l}\text { Intravenously administered polyclonal } \\
\text { immunoglobulin ( } 5 \text { days) completed }\end{array}$ \\
\hline 12 & & $\begin{array}{l}\text { CSF studies - pus cells - nil, lymphocytes } \\
2 / \mu \mathrm{l} \text {, protein } 20 \mathrm{mg} / \mathrm{dl} \text {, sugar } 80 \mathrm{mg} / \mathrm{dl} \\
\text { (random blood sugar } 131 \mathrm{mg} / \mathrm{dl} \text { ) }\end{array}$ & \\
\hline 13 & & & Discharged from ward \\
\hline 20 & $\begin{array}{l}\text { Clinic review - complete neurological } \\
\text { resolution }\end{array}$ & & Discharged from clinic \\
\hline
\end{tabular}

CSF cerebrospinal fluid, CT computed tomography, MRI magnetic resonance imaging, NS-1 non-structural protein $1, R T$-PCR reverse transcriptase-polymerase chain reaction 
aminotransferase (ALT) was $55 \mathrm{U} / \mathrm{l}$ on day 3 , increased to $127 \mathrm{U} / \mathrm{l}$ on day 5 , and normalized to $37 \mathrm{U} / \mathrm{l}$ by day 10 . Other liver functions were normal. His erythrocyte sedimentation rate was 18 in the first hour and C-reactive protein was $32 \mathrm{mg} / \mathrm{l}$. Urine analysis and an ultrasound scan of his abdomen were normal.

A dengue non-structural protein 1 (NS-1) antigen test by rapid diagnostic test and real-time reverse transcriptase-polymerase chain reaction (RT-PCR) done on the third day of illness and dengue IgM antibodies by enzyme-linked immunosorbent assay (ELISA) tested on the seventh day of illness were positive. Serum IgM antibodies to West Nile virus and Japanese encephalitis virus by ELISA were negative on day 7. Nerve conduction studies showed evidence of mild axonal polyneuropathy. Repetitive nerve stimulation did not show decrement. Computed tomography (CT) and magnetic resonance imaging (MRI) scans of his brain were normal. Cerebrospinal fluid (CSF) analysis performed on the 12th day of illness after recovery of thrombocytopenia was normal with no albuminocytologic dissociation. PCR for dengue virus and dengue IgM antibodies in CSF were negative. Antibodies (IgG, IgM, and IgA) against a panel of gangliosides including GQ1b and GT1a were negative.

DF was treated with fluid replacement at $100 \mathrm{ml} /$ hour while monitoring for plasma leakage clinically and ultrasonically. His fever subsided after 5 days from onset and all hematological parameters returned to normal subsequently. He was treated with intravenously administered immunoglobulin $0.4 \mathrm{~g} / \mathrm{kg}$ for 5 days starting from the fourth day of his illness. He required nasogastric feeding because of dysphagia. He was treated with swallowing and speech therapy, and gait and balance training.

From around the sixth day of illness, his ptosis and ophthalmoplegia began to improve gradually. His ataxia improved enabling him to walk without support from the eighth day onward. He was discharged from hospital on the 13th day of illness and continued nasogastric feeding, physiotherapy, and speech therapy at home. At review 1 week later, he had made a complete neurological recovery with normal swallowing, complete eye movements, normal gait, and re-emerged deep tendon reflexes.

\section{Discussion and conclusions}

Acute onset of the triad of ophthalmoplegia, areflexia, and ataxia defines the syndrome of MFS. Although not typical, bulbar paralysis has been reported in up to $60 \%$ of patients with MFS [7-9]. The constellation of symptoms and signs in our patient was consistent with MFS. Among the differential diagnoses considered, myasthenia gravis was ruled out on the basis of pupillary involvement, areflexia, and lack of fatigability while Bickerstaff brainstem encephalitis was ruled out based on the lack of upper motor neuron signs, intact sensorium, and normal brain images on MRI. Furthermore, an essentially normal nerve conduction study, apart from mild axonal polyneuropathy related to longstanding diabetes, is consistent with MFS [10]. Although the typical CSF finding in GBS describes albuminocytologic dissociation, normal protein levels have been reported in MFS [11]. Serum anti-GQ1b antibodies are highly sensitive and confirmatory of a clinical diagnosis of MFS [10], but were negative in our patient supporting the hypothesis of direct viral neurotropism rather than immune-mediated injury.

Although rare, GBS has been reported as a neurological manifestation of dengue infection $[4,6]$. It usually occurs after the acute phase of the dengue infection suggesting an immunological basis for its manifestation. Reports of concomitant onset of both dengue and GBS are scarce. In a case series from Rio de Janeiro, out of seven patients with GBS who were positive for dengue IgM, one patient had concomitant dengue infection and GBS. However, available clinical information does not provide convincing evidence for the diagnosis of DF while the authors claimed that they were unable to exclude other infections [12]. There are a few other case reports of GBS occurring during DF [13, 14]. In contrast, there is only one case report of probable MFS associated with DF, but this could not be critically appraised due to the unavailability of English text of the article [15]. Our patient did not have any preceding infection or vaccination to suggest the usual immune-mediated basis for MFS. Negative PCR assays and IgM antibodies in CSF does not exclude acute CNS infection by dengue virus since these tests can be negative in many owing to low viral loads and low sensitivity of IgM in CSF [6]. A lumbar puncture had to be delayed until recovery of thrombocytopenia. Zika virus has been reported to cause GBS as a parainfectious manifestation more than as a postinfectious consequence [16]. The mechanisms postulated in the development of GBS in Zika virus infection include immune-mediated molecular mimicry during the incubation period, direct viral neuropathogenic effects, a hyperacute immune response, or immune mechanisms other than molecular mimicry [17]. It is plausible that similar mechanisms occur when GBS or MFS occur as a parainfectious manifestation of dengue infection. There is evidence that dengue virus can actively penetrate the blood-brain barrier to enter the central nervous system [16]. Neurotropism of dengue virus is well recognized [4] in causing dengue encephalitis, but there have not been studies so far to demonstrate dengue virus in the peripheral nervous system.

This case report highlights the potential for neurotropism of dengue virus in the peripheral nervous system to cause MFS as a parainfectious rather than a postinfectious manifestation of flaviviral infection. 


\section{Abbreviations}

ALT: Alanine aminotransferase; AST: Aspartate aminotransferase; CSF: Cerebrospinal fluid; CT: Computed tomography; DF: Dengue fever; DHF: Denque hemorrhagic fever; ELISA: Enzyme-linked immunosorbent assay; GBS: Guillain-Barré syndrome; MFS: Miller Fisher syndrome; MRI: Magnetic resonance imaging; PCR: Polymerase chain reaction; RT: Reverse transcriptase

\section{Acknowledgements}

The authors gratefully acknowledge Dr Susan Halstead of the Institute of Infection, Immunity and Inflammation, College of Medical, Veterinary and Life Sciences, University of Glasgow, Scotland for assaying antibodies against neuronal gangliosides in our patient.

\section{Funding}

Not applicable.

\section{Availability of data and materials}

Not applicable.

\section{Authors' contributions}

NLdS, PW, and TC were involved in the care of the patient. NM and TU were involved in serological and molecular diagnostics of the patient. NLdS wrote the initial draft of the manuscript. PW, NM, TU, and TC critically appraised and revised the overall content of the manuscript. All authors read and approved the manuscript.

\section{Authors' information}

Dr Nipun Lakshitha de Silva

Postgraduate trainee in clinical medicine at the Professorial Unit in Medicine, National Hospital of Sri Lanka and lecturer (probationary) in Clinical Medicine, Faculty of Medicine, General Sir John Kotelawala Defence University. Dr Praveen Weeratunga

Lecturer in Medicine, Faculty of Medicine, University of Colombo Senior Registrar in Medicine, Professorial Medical Unit, National Hospital of Sri Lanka

Thirugnanam Umapathi

Senior Consultant Neurologist, National Neuroscience Institute, Singapore Neelika Malavige

Director, Centre for Dengue Research, University of Sri Jayewardenepura Prof. Thashi Chang

Professor in Neurology in the Department of Clinical Medicine at the University of Colombo, Sri Lanka and honorary Consultant Neurologist at the Professorial Unit in Medicine, National Hospital of Sri Lanka

\section{Ethics approval and consent to participate}

Not applicable.

\section{Consent for publication}

Written informed consent was obtained from the patient for publication of this case report and any accompanying images. A copy of the written consent is available for review by the Editor-in-Chief of this journal.

\section{Competing interests}

The authors declare that they have no competing interests.

\section{Publisher's Note}

Springer Nature remains neutral with regard to jurisdictional claims in published maps and institutional affiliations.

\section{Author details}

${ }^{1}$ Professorial Unit in Medicine, National Hospital of Sri Lanka, Colombo, Sri Lanka. ${ }^{2}$ Department of Clinical Medicine, Faculty of Medicine, University of Colombo, Colombo, Sri Lanka. ${ }^{3}$ Department of Neurology, National Neuroscience Institute, $11 \mathrm{Jln}$ Tan Tock Seng, Singapore. ${ }^{4}$ Centre for Dengue Research, University of Sri Jayewardenepura, Gangodawila, Sri Lanka.
Received: 17 January 2018 Accepted: 2 April 2019

Published online: 02 May 2019

\section{References}

1. World Health Organization. Dengue: guidelines for diagnosis, treatment, prevention and control. Geneva: World Health Organization; 2009.

2. Bhatt S, Gething PW, Brady OJ, Messina JP, Farlow AW, Moyes CL, Drake JM, Brownstein JS, Hoen AG, Sankoh O. The global distribution and burden of dengue. Nature. 2013;496:504.

3. Solomon T, Dung NM, Vaughn DW, Kneen R, Raengsakulrach B, Loan HT, Day NP, Farrar J, Myint KS, Warrell MJ. Neurological manifestations of dengue infection. Lancet. 2000;355:1053-9.

4. Verma R, Sahu R, Holla V. Neurological manifestations of dengue infection: a review. J Neurol Sci. 2014;346:26-34.

5. Withana M, Rodrigo C, Chang T, Karunanayake P, Rajapakse S. Dengue fever presenting with acute cerebellitis: a case report. BMC Res Notes. 2014;7:125.

6. Carod-Artal FJ, Wichmann O, Farrar J, Gascon J. Neurological complications of dengue virus infection. Lancet Neurol. 2013;12:906-19.

7. Wakerley BR, Uncini A, Yuki N. Guillain-Barré and Miller Fisher syndromes - new diagnostic classification. Nat Rev Neurol. 2014;10:537-44.

8. Lyu R-K, Tang L-M, Cheng S-Y, Hsu W-C, Chen S-T. Guillain-Barré syndrome in Taiwan: a clinical study of 167 patients. J Neurol Neurosurg Psychiatry. 1997;63:494-500.

9. Mori M, Kuwabara S, Fukutake T, Yuki N, Hattori T. Clinical features and prognosis of Miller Fisher syndrome. Neurology. 2001;56:1 104-6.

10. Aranyi Z, Kovacs T, Sipos I, Bereczki D. Miller Fisher syndrome: brief overview and update with a focus on electrophysiological findings. Eur J Neurol. 2012;19:15-20. e11-13

11. Wong AH, Umapathi T, Nishimoto Y, Wang YZ, Chan YC, Yuki N. Cytoalbuminologic dissociation in Asian patients with Guillain-Barré and Miller Fisher syndromes. J Peripher Nerv Syst. 2015;20:47-51.

12. Soares CN, Cabral-Castro M, Oliveira C, Faria LC, Peralta JM, MR F, PuccioniSohler M. Oligosymptomatic dengue infection: a potential cause of Guillain Barré syndrome. Arq Neuropsiquiatr. 2008;66:234-7.

13. Sharma CM, Kumawat B, Ralot T, Tripathi G, Dixit S. Guillain-Barre syndrome occurring during dengue fever. J Indian Med Assoc. 2011;109:675-82.

14. Simon O, Billot S, Guyon D, Daures M, Descloux E, Gourinat AC, Molko N, Dupont-Rouzeyrol M. Early Guillain-Barré Syndrome associated with acute dengue fever. J Clin Virol. 2016;77:29-31.

15. Gaultier C, Angibaud G, Laille M, Lacassin F. Probable Miller Fisher syndrome during dengue fever type 2. Rev Neurol. 2000;156:169-71.

16. Domingues RB, Kuster GW, Onuki-Castro FL, Souza VA, Levi JE, Pannuti CS. Involvement of the central nervous system in patients with dengue virus infection. J Neurol Sci. 2008;267:36-40.

17. Parra B, Lizarazo J, Jiménez-Arango JA, Zea-Vera AF, González-Manrique G, Vargas J, Angarita JA, Zuñiga G, Lopez-Gonzalez R, Beltran CL. Guillain-Barré syndrome associated with Zika virus infection in Colombia. N Engl J Med. 2016;375:1513-23.

\section{Ready to submit your research? Choose BMC and benefit from:}

- fast, convenient online submission

- thorough peer review by experienced researchers in your field

- rapid publication on acceptance

- support for research data, including large and complex data types

- gold Open Access which fosters wider collaboration and increased citations

- maximum visibility for your research: over $100 \mathrm{M}$ website views per year

At BMC, research is always in progress.

Learn more biomedcentral.com/submissions 